\title{
Acute In Vivo Genetic Rescue Demonstrates That Phosphorylation of RIM1 $\alpha$ Serine 413 Is Not Required for Mossy Fiber Long-Term Potentiation
}

\author{
Ying Yang and Nicole Calakos \\ Center for Translational Neuroscience, Departments of Neurology and Neurobiology, Duke University Medical Center, Durham, North Carolina 27710
}

While presynaptic, protein kinase A (PKA)-dependent, long-term plasticity has been described in numerous brain regions, the target(s) of PKA and the molecular mechanisms leading to sustained changes in neurotransmitter release remain elusive. Here, we acutely reconstitute mossy fiber long-term potentiation (mfLTP) de novo in the mature brains of mutant mice that normally lack this form of plasticity. These results demonstrate that RIM1 $\alpha$, a presynaptic scaffold protein and a potential PKA target, can support mfLTP independent of a role in brain development. Using this approach, we study two mutations of RIM1 $\alpha$ (S413A and V415P) and conclude that PKA-phosphorylation-dependent signaling by RIM1 $\alpha$ serine 413 is not required for mfLTP, consistent with conclusions reached from the study of RIM1 $\alpha$ S413A knockin mice. Together, these results provide insights into the mechanism of mossy fiber LTP and demonstrate a useful acute approach to genetically manipulate mossy fiber synapses in the mature brain.

\section{Introduction}

Synaptic plasticity, the modulation of synaptic efficacy, has long been considered to be a primary neural mechanism for learning and memory (Kandel, 2001; Fusi et al., 2005). Synaptic plasticity may be expressed either presynaptically, through changes in neurotransmitter release, or postsynaptically, through alterations in neurotransmitter receptor activity or localization. Many forms of presynaptic long-term plasticity require signaling through cAMP and cAMP-dependent protein kinase A (PKA) (Huang et al., 1994; Weisskopf et al., 1994; Weisskopf and Nicoll, 1995; Tzounopoulos et al., 1998; Villacres et al., 1998; Nguyen and Woo, 2003, Chevaleyre et al., 2007). In addition to PKA signaling, a requirement for the presynaptic proteins Rab3a and RIM1 $\alpha$ has also been demonstrated (Castillo et al., 1997, 2002; Chevaleyre et al., 2007; Fourcaudot et al., 2008). Yet, how the activities of these components are orchestrated to produce long-lasting changes in synaptic efficacy remains poorly understood.

RIM $1 \alpha$ is an active zone scaffold protein that binds to many presynaptic proteins involved in neurotransmitter release and synapse formation (Wang et al., 1997, 2000, 2002; Zhen and Jin, 1999; Betz et al., 2001; Coppola et al., 2001; Wang et al., 2001; Ohtsuka et al., 2002; Schoch et al., 2002; Sun et al., 2003; Kiyonaka et al., 2007). RIM1 $\alpha$ has been shown to be required for PKA-

Received Aug. 25, 2009; revised Dec. 21, 2009; accepted Dec. 28, 2009.

This work was supported by National Institute of Neurological Disorders and Stroke Grants P01(NS053862) and K02 (NS054840) to N.C. We thank Yuanji Pan and Samantha Tracy for outstanding technical assistance, Thomas Südhof for providing RIM1 $\alpha^{-/-}$mice, Jing Lu for guidance with in vivo techniques, members of the Calakos lab for stimulating discussions, and Drs. G. Augustine, J. McNamara, R. Mooney, and A. West for critical reading of this manuscript.

Correspondence should be addressed to Nicole Calakos at the above address. E-mail: nicole.calakos@duke.edu. DOI:10.1523/JNEUROSCI.4285-09.2010

Copyright $\odot 2010$ the authors $\quad 0270-6474 / 10 / 302542-05 \$ 15.00 / 0$ dependent, presynaptic long-term potentiation (LTP) at hippocampal mossy fiber synapses, cerebellar parallel fiber synapses (Castillo et al., 2002) and cortical-lateral amygdala synapses (Fourcaudot et al., 2008), as well as PKA-dependent, presynaptic long-term depression (LTD) at hippocampal inhibitory synapses (Chevaleyre et al., 2007). Because RIM1 $\alpha$ contains PKA phosphorylation sites, it has been proposed to be the downstream effector of PKA signaling in presynaptic long-term plasticity (Lonart et al., 2003; Südhof, 2004). This hypothesis was strengthened by the observation that acutely expressing RIM $1 \alpha$ with a mutated PKA phosphorylation site failed to restore presynaptic LTP to RIM1 $\alpha^{-1-}$ neurons and suppressed LTP in wild-type neurons that were cultured from embryonic cerebellum (Lonart et al., 2003). However, examination of a knockin mouse with this same mutation (S413A) failed to find any defects in presynaptic LTP, either at parallel fiber or mossy fiber synapses (Kaeser et al., 2008). These conflicting results raise concerns that the expression of presynaptic LTP in the knockin mouse may have resulted from developmental compensation and/or that the results from cultured neurons may not accurately reflect in vivo mechanisms.

Therefore, we sought to address the role of PKA-mediated phosphorylation of serine 413 in mossy fiber LTP (mfLTP) by means of acute genetic manipulation in the mature brain. Here, we describe a method to reconstitute mfLTP de novo by genetically manipulating hippocampal granule cells in the adult brain through in vivo viral injection. Our approach bypasses the issue of developmental compensation inherent to knockin strategies and avoids concerns about ex vivo neuronal differentiation, synapse development, and connectivity that are raised by cultured neuron preparations. We demonstrate that mfLTP can be acutely restored in RIM $1 \alpha^{-1-}$ mice when RIM1 $\alpha$ is expressed only briefly in the mature brain, indicating that RIM1 $\alpha$ is not required during the major developmental period of synapse formation for its role in mfLTP. We further show that phos- 
phorylation of RIM1 $\alpha$ serine 413 is not required to acutely restore mfLTP in the mature, developed brain.

\section{Materials and Methods}

Plasmids and concentrated Sindbis virus preparation. Rat RIM $1 \alpha$ cDNA was kindly provided by Dr. Thomas Südhof (Stanford University, Palo Alto, CA) and contains the $\Delta 83-105$ splice variant at splice site A (Wang et al., 1997; Lonart et al., 2003). RIM1 $\alpha$ cDNA was subcloned into the pSINrep $\left(n s P 2 S^{726}\right)$ vector (provided by Dr. P. Osten, Cold Spring Harbor Laboratory, Cold Spring Harbor, NY) (Kim et al., 2004). An internal ribosomal entry sequence (IRES) and enhanced green fluorescence protein (EGFP) cDNA were subcloned from pSR5I2E (Marie et al., 2005) and inserted 3' of the RIM1 $\alpha$ cDNA. Missense mutations were introduced using the Quikchange Site-Directed Mutagenesis Kit (Stratagene). Recombinant Sindbis virus was generated according to the manufacturer's instructions (Invitrogen). In vitro transcription was performed using Ambion mMESSAGE mMACHINE SP6 kit (Applied Biosystems/Ambion) and products were electroporated into BHK21 cells. Recombinant viral particles were harvested $60-72 \mathrm{~h}$ after electroporation, purified by centrifugation at $3000 \mathrm{rpm}$ (Marathon 22K centrifuge, Fisher Scientific), and concentrated by ultracentrifugation at 100,000 $\times g$ (Beckman L8M ultracentrifuge, Beckman Coulter). The pellet was resuspended in PBS. Viral titers were estimated to be $0.5-1 \times 10^{6} \mathrm{TU} / \mu \mathrm{l}$ for all viruses as detected by EGFP fluorescence following HEK cell infection. Control virus expressed only EGFP downstream of the IRES. Test viruses expressed RIM $1 \alpha$ cDNA upstream of the IRES and EGFP. Viral identities were unknown to the investigator during in vivo injection, data acquisition, and analysis.

Stereotaxic injection. All surgeries were performed in accordance with guidelines for humane care and handling of rodents and with approval from our Institutional Animal Care and Use Committee. To reduce procedural variability, surgeries were performed on batches of 4-10 mice at a time. Four-week-old mice were anesthetized with avertin (2-2-2 tribromoethanol) intraperitoneally and placed in a stereotaxic mouse head holder (David Kopf Instruments). Fifty nanoliters of concentrated $\mathrm{nsP} 2 \mathrm{~S}^{726}$ modified Sindbis virus were injected (flow rate of $23 \mathrm{nl} / \mathrm{s}$ ) into the dentate gyrus of the hippocampus bilaterally at six different depths. The initial injection coordinates relative to bregma were anterior 1.95 $\mathrm{mm}$, mediolateral $1.2 \mathrm{~mm}$, and dorsoventral $2.00 \mathrm{~mm}$. Additional $50 \mathrm{nl}$ injections occurred each $0.05 \mathrm{~mm}$ during withdrawal of the injection cannula. Virus was delivered using Nanoject II (Drummond Scientific), and the cannula remained at each location for $1 \mathrm{~min}$ following each injection.

RIM1 $\alpha^{-1-}$ mice were obtained as previously described (Schoch et al., 2002) and backcrossed to c57/Bl6 at least six times before use. To further reduce genetic background variability, experiments testing viral effect on mfLTP in RIM1 $\alpha^{-1-}$ mice were performed on littermates. Littermate $\operatorname{RIM} 1 \alpha^{-1-}$ mice were obtained from $\operatorname{RIM} 1 \alpha^{-1-} \times \operatorname{RIM} 1 \alpha^{-1-}$ or RIM $1 \alpha^{-1-} \times \operatorname{RIM} 1 \alpha^{+/-}$breedings so that sufficient numbers of RIM $1 \alpha^{-1-}$ mice (i.e., more than one) could be obtained per litter. All homozygote parents of experimental subjects were obtained from the breeding colony, which was maintained exclusively by RIM $1 \alpha^{+/-} \times$ $\operatorname{RIM} 1 \alpha^{+/-}$matings. Experiments testing the effect of control EGFP virus infection on mfLTP in wild-type mice were performed on wild-type mice obtained from RIM $1 \alpha^{+/-} \times \operatorname{RIM} 1 \alpha^{+/-}$breedings.

Electrophysiology. Four to seven days after viral injection, acute transverse hippocampal slices (300 $\mu \mathrm{m}$ thick) from virus-injected mice were prepared and used for experiments. Infected slices were selected for use in experimental recordings by the presence of EGFP fluorescence detectable in more than half of the area of the dentate gyrus viewed in the horizontal plane (Fig. $1 \mathrm{~B}$ ). Recordings were done in normal artificial CSF containing (in mM): $119 \mathrm{NaCl}, 2.5 \mathrm{KCl}, 1.3 \mathrm{MgSO}_{4}, 2.5 \mathrm{CaCl}_{2}, 1.0$ $\mathrm{NaH}_{2} \mathrm{PO}_{4}, 26.2 \mathrm{NaHCO}_{3}$ and 10 D-glucose, saturated with $95 \% \mathrm{O}_{2}$ and $5 \% \mathrm{CO}_{2}$, and perfused at $2 \mathrm{ml} / \mathrm{min}$. A monopolar stimulation electrode with $2 \mathrm{M} \mathrm{NaCl}$ was placed in a region of stratum granulosum with EGFP fluorescence. Mossy fiber responses were monitored at room temperature by extracellular field EPSPs (fEPSPs) from the stratum lucidum in the CA3 area at a frequency of $0.05 \mathrm{~Hz}$ unless otherwise indicated. Baseline stimulation was adjusted to yield fEPSP responses between 0.4 and $0.7 \mathrm{mV}$. The average stimulus intensity was $0.33 \pm 0.03 \mathrm{~mA}$ for control
EGFP viral slices and $0.29 \pm 0.03 \mathrm{~mA}$ for test RIM viruses $(p=0.18)$. Mossy fiber contribution to the field potentials was confirmed at the end of each experiment by sensitivity to pharmacological blockade by $3 \mu \mathrm{M}$ DCG-IV, a group II metabotropic glutamate receptor agonist that selectively suppresses mossy fiber synaptic transmission (Gibson et al., 2005; Nicoll and Schmitz, 2005). Data were included only if the remaining response was $<10 \%$ of the initial baseline response. Mossy fiber LTP was induced by a single tetanus at time $0 \min (25 \mathrm{~Hz}$ for $5 \mathrm{~s})$ in the presence of an NMDA-type antagonist (50 $\mu \mathrm{M} \mathrm{APV)} \mathrm{during} \mathrm{tetanic} \mathrm{induction} \mathrm{as}$ previously described (Castillo et al., 2002). Mossy fiber LTP is reported as the average fEPSP amplitude during the period 50-60 min post-tetanus relative to the baseline period ( $10 \mathrm{~min}$ before tetanus). Data were acquired at $10 \mathrm{kHz}$ and filtered at $1 \mathrm{kHz}$.

Data analysis. All summary data are presented as the mean \pm SEM as a percentage of the baseline. To avoid false-positives from multiple testing, repeated measure ANOVA and Kruskal-Wallis test were performed on all data from different groups ( 66 slices total, 7 groups, $p<10^{-3}$ for both tests). Subsequent ad hoc comparisons were performed using Student's $t$ test and Wilcoxon rank order test. Both tests yielded similar conclusions. For brevity, only results from Student's $t$ test are presented. In all figures, an asterisk $\left.{ }^{*}\right)$ indicates $p<0.05$; exact values are stated in text.

\section{Results}

\section{Acute expression of RIM1 $\alpha$ in $\operatorname{RIM} 1 \alpha^{-/-}$mice restores mossy} fiber LTP

To acutely rescue mfLTP in RIM $1 \alpha^{-1-}$ mice, we took advantage of the high infectivity and low toxicity of an nsP2S ${ }^{726}$ mutant Sindbis virus. The $\mathrm{S}^{726}$ mutation of the nsP2 protein impairs the ability of the virus to shut down host protein synthesis and has markedly reduced toxicity (supplemental Fig. 1, available at www.jneurosci.org as supplemental material) (Dryga et al., 1997; Jeromin et al., 2003; Kim et al., 2004). To manipulate synapses in the most physiological setting, virus was delivered to the dentate gyrus of 4-week-old mice by in vivo stereotaxic injection. We observed that nsP2S ${ }^{726}$ Sindbis virus had a very high infectivity of granule cells (30-92\%) (supplemental Fig. 2 and supplemental Methods, available at www.jneurosci.org as supplemental material) such that we could routinely visualize EGFP fluorescence in greater than half of the area of the dentate gyrus (viewed in the horizontal plane of acute transverse hippocampal slices) (Fig. $1 B)$. We reasoned that this high degree of infectivity should produce a detectable effect at the population level; therefore, we chose to monitor synaptic responses using fEPSPs. In this way, variability related to uncertain connectivity of any individual postsynaptic cell was minimized. To decrease variation due to degree of infection, only slices with $>50 \%$ of the dentate gyrus fluorescent were used for recording.

In RIM $1 \alpha^{-1-}$ slices infected with the control EGFP virus, mossy fiber fEPSP responses displayed characteristic properties of short-term plasticity and sensitivity to the group II metabotropic glutamate receptor agonist, DCG-IV, and were similar to those observed in noninjected control slices (supplemental Fig. $3 A, B$, available at www.jneurosci.org as supplemental material). Similarly, infection by the control EGFP virus did not alter synaptic responses in RIM $1 \alpha^{-/-}$slices following the mfLTP induction protocol, nor did it impair the degree of potentiation in RIM $1 \alpha^{+/+}$slices (supplemental Fig. 3C,D, available at www. jneurosci.org as supplemental material). These findings indicate that the in vivo viral manipulation of hippocampal granule cells does not significantly alter mossy fiber responses.

We next examined whether acute expression of RIM $1 \alpha$ in hippocampal granule cells in the mature brain was able to rescue mfLTP in RIM $1 \alpha^{-/-}$mice. Following mfLTP induction, evoked mossy fiber responses from slices expressing RIM $1 \alpha$ exhibited long-lasting potentiation of fEPSPs (Fig. 1C,D; supplemental Fig. 
4, available at www.jneurosci.org as supplemental material) (RIM1 $\alpha 135 \pm 6 \%$, 11 slices/7 mice). In contrast, slices expressing the EGFP control virus failed to exhibit appreciable mfLTP (EGFP $114 \pm$ $4 \%, 12$ slices $/ 5$ mice; $p=0.009$ RIM $1 \alpha$ vs EGFP in RIM $1 \alpha^{-1-}$ slices). The average percentage of mfLTP after RIM virus infection in RIM $1 \alpha^{-1-}$ slices is $\sim 70 \%$ of that observed in wild-type $\operatorname{RIM} 1 \alpha^{+/+}$ slices (Fig. 1C,D) (EGFP in RIM $1 \alpha^{+/+}$ slices $151 \pm 6 \%, 6$ slices $/ 3$ mice; $p=0.096$ RIM1 $\alpha$ in RIM $1 \alpha^{-/-}$slices vs EGFP in RIM $1 \alpha^{+/+}$slices). This is not surprising given that the extracellular field potentials represent activity from a population average of infected and uninfected cells. However, it is notable that, in some experiments, we do obtain mfLTP values comparable to the highest noted in wild-type recordings suggesting that it is possible to rescue to wild-type levels (data not shown).

We next evaluated whether acute expression of RIM1 $\alpha$ altered short-term plasticity of mossy fiber synapses. We found no significant changes in paired-pulse ratios, frequency facilitation or sensitivity to DCG-IV as a result of acute RIM1 $\alpha$ expression (Fig. $1 E, F)$. These findings in conjunction with a previous study, which demonstrated that embryonic deletion of RIM1 $\alpha$ did not change mossy fiber short-term plasticity (Castillo et al., 2002), suggest that RIM1 $\alpha$ plays a significant role in long-term but not short-term plasticity at these synapses.

\section{The phosphorylation site-deficient} mutant of RIM1 $\alpha$ rescues mossy fiber LTP in RIM1 $\alpha^{-/-}$mice

Using this acute, in vivo rescue approach, we examined the role of RIM1 $\alpha$ serine 413 phosphorylation in mfLTP. A serine to alanine substitution at amino acid 413 was made to prevent phosphorylation at this site, as had been done in previous studies (Lonart et al., 2003; Kaeser et al., 2008). Following S413A mutant RIM1 $\alpha$ viral infection, robust mfLTP could still be observed (Fig. 2) (145 $\pm 7 \%, 12$ slices/ 6 mice; $p=0.001$ compared with EGFP; $p=0.28$ compared with $\mathrm{RIM} 1 \alpha)$. These results indicate that acute expression of either S413A mutant or wild-type RIM1 $\alpha$ in hippocampal granule cells can restore mfLTP in young adult $\operatorname{RIM} 1 \alpha^{-/-}$mice.

\section{The enhanced-14-3-3-binding mutant of RIM1 $\alpha$ does not} occlude LTP at mossy fiber synapses in RIM1 $\alpha^{-/-}$mice It has been proposed that phosphoserine-dependent binding of 14-3-3 proteins to RIM1 $\alpha$ at the $\$ 413$ residue is also required for the expression of presynaptic LTP. In support of this idea, a V415P mutation of RIM1 $\alpha$, which markedly enhances phosphoserine 413 binding to $14-3-3$ proteins in vitro, has been shown to enhance basal release and occlude LTP in cerebellar cultures from
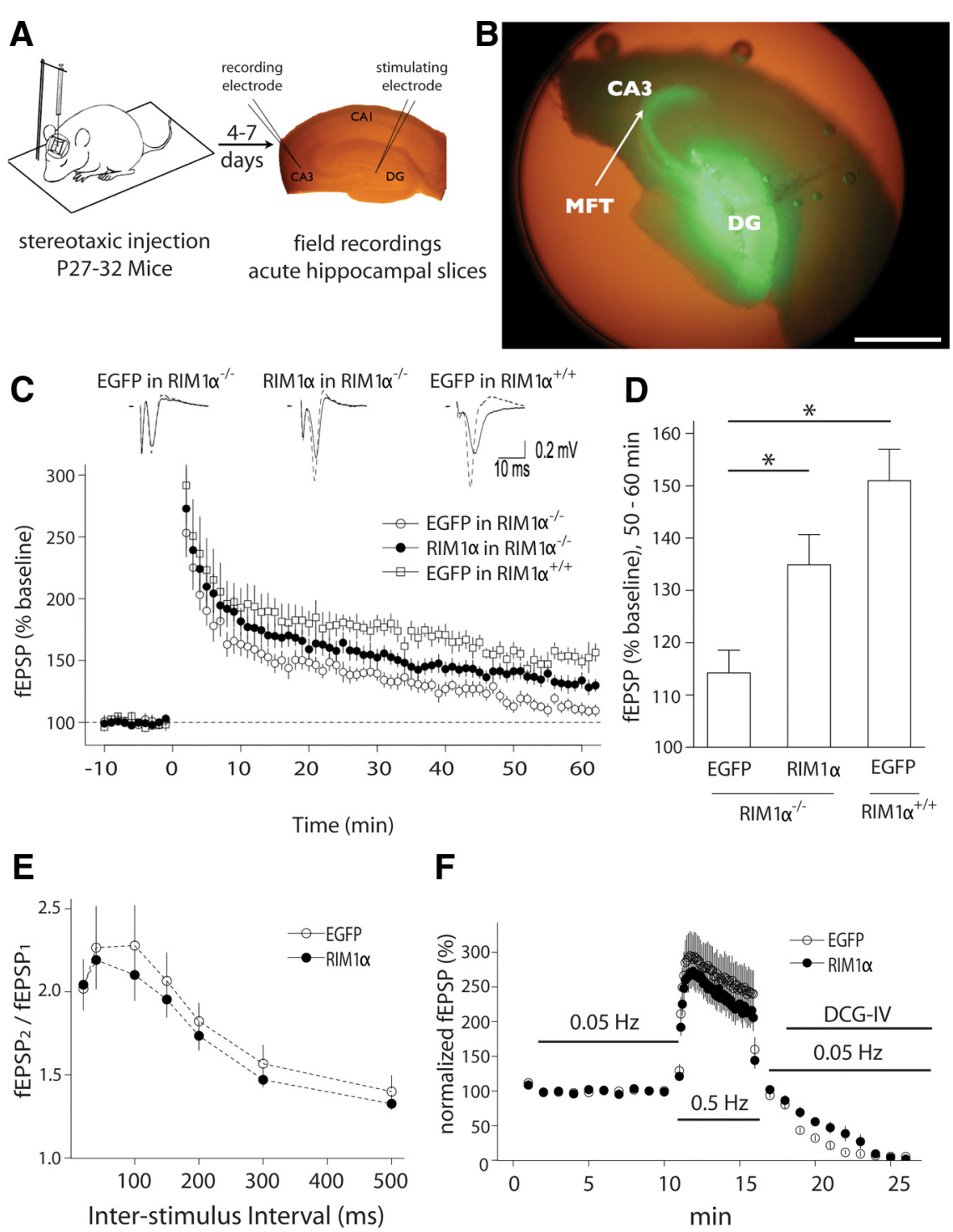

$\mathbf{F}$

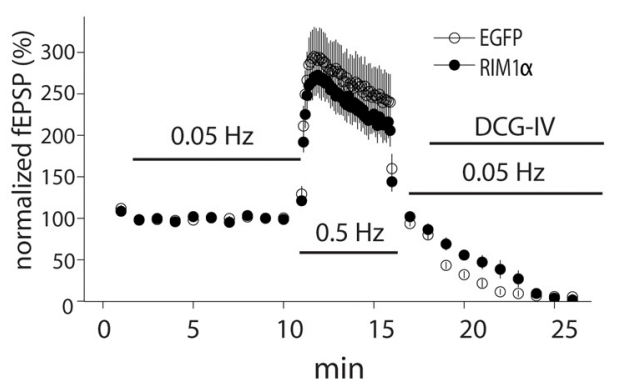

Figure 1. Postnatal viral-mediated expression of RIM1 $\alpha$ rescues mossy fiber LTP in RIM $1 \alpha^{-1-}$ mice, without altering short-term plasticity. $\boldsymbol{A}$, Schematic representation of the experimental strategy. $\boldsymbol{B}$, Representative example of an acute hippocampal slice expressing xample traces are an average of three responses obtained over $1 \mathrm{~min}$ from periods immediately before (solid trace) and $60 \mathrm{~min}$ after dashed trace) tetanus. $\boldsymbol{D}$, Mean level of mfLTP measured from 50 to 60 min after tetanus. Sample sizes for C, D were: EGFP in RIM1 $\alpha^{-/}$

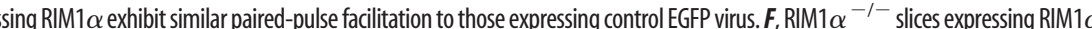
were: EGFP 11 slices/3 mice; RIM1 $\alpha$ s slices/3 mice. Horizontal bar indicates stimulation frequency and period of drug application. DG, Dentate gyrus; MFT, mossy fiber tract.

RIM1 $\alpha^{-1-}$ mice (Simsek-Duran et al., 2004). These observations provide a second opportunity to test the relevance of $\mathrm{S} 413$ phosphorylation in our in vivo rescue platform. In contrast to the cerebellar culture results, acute in vivo expression of V415P mutant RIM $1 \alpha$ was able to rescue mfLTP (Fig. 3) (149 $\pm 10 \%, 12$ slices/7 mice; $p=0.004$ compared with EGFP; $p=0.25$ compared with $\operatorname{RIM} 1 \alpha$ ). Thus, two distinct mutations that interfere with phosphoserine-dependent signaling of RIM1 $\alpha$ at the S413 site demonstrate that this is not a requirement for the expression of presynaptic LTP at mossy fiber synapses.

\section{Discussion}

In contrast to the ease of manipulation and advances in understanding postsynaptic physiology enabled by acute genetic ma- 


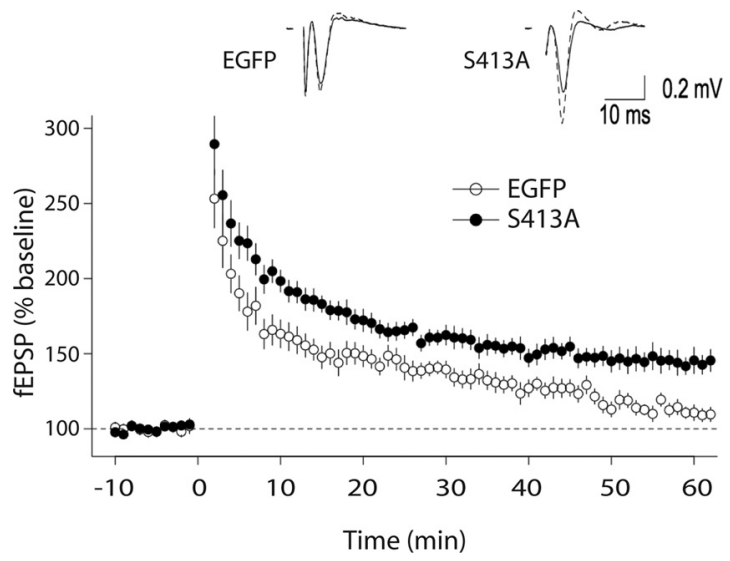

Figure 2. Postnatal viral-mediated expression of S413A mutant RIM1 $\alpha$ rescues mfLTP in RIM1 $\alpha^{-1-}$ mice. Traces are from periods immediately before (solid trace) and $60 \mathrm{~min}$ after (dashed trace) tetanus. Sample sizes were: $\mathrm{EGFP}, 12$ slices $/ 5$ mice; $\$ 413 \mathrm{~A}, 12$ slices $/ 6$ mice.

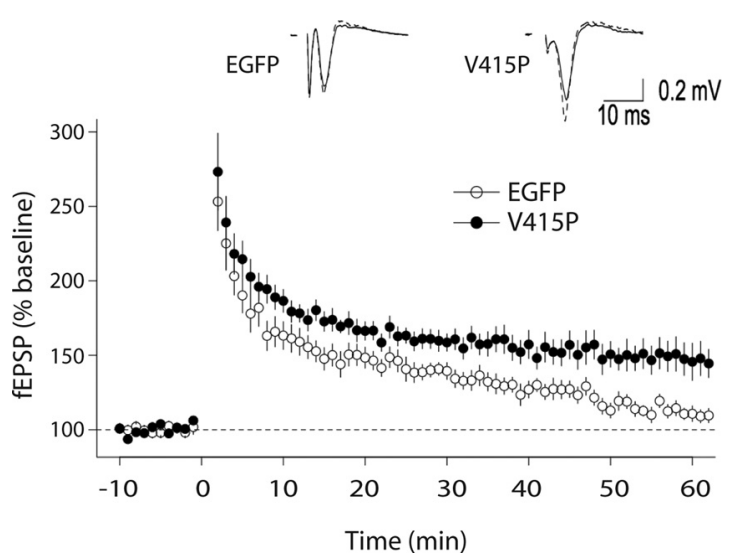

Figure 3. Postnatal viral-mediated expression of the enhanced 14-3-3 binding mutant V415P of RIM $1 \alpha$ rescues mfLTP in RIM1 $\alpha^{-1-}$ mice. Traces are from periods immediately before (solid trace) and $60 \mathrm{~min}$ after (dashed trace) tetanus. Sample sizes were: EGFP, 12 slices/5 mice; $\vee 415 P, 12$ slices/7 mice.

nipulation of postsynaptic proteins (Pettit et al., 1994; Lissin et al., 1998; Takahashi et al., 2003), similar investigations of presynaptic physiology have been far more limited. Unlike the study of postsynaptic proteins, where one can directly patch on a neuron that expresses a fluorescent marker indicating infection and modification of all postsynaptic sites, acute manipulation of presynaptic proteins is limited by technical hurdles related to the often sparse and variable connectivity of genetically modified inputs to postsynaptic cells. Previous methods for overcoming this limitation have included using paired recordings of presynaptic and postsynaptic cells (Lonart et al., 2003; Wimmer et al., 2004; Young and Neher, 2009), autaptic cultured neurons in which a single cell synapses only with itself (Rhee et al., 2002), and herpes viral infection of rat granule cells to inhibit mfLTP (Dumas et al., 1999). However, these methodologies present significant limitations. First, not all brain circuits have sufficient connectivity in brain slices to make paired recordings feasible, as is the case between the dentate gyrus and CA3 (Nicoll and Schmitz, 2005). Second, culture models raise the possibility of divergence from in vivo mechanisms. Third, few viruses can achieve both the high infectivity and low toxicity necessary to overcome issues raised by low or variable connectivity of genetically modified inputs. As a result, most studies investigating the molecular mechanisms of presynaptic LTP have relied upon the generation of transgenic mouse models (Castillo et al., 1997, 2002; Villacres et al., 1998; Kaeser et al., 2008) — an approach that is costly, time-intensive, and makes it difficult to distinguish direct effects from those resulting from developmental compensation. Here we provide a novel approach for investigating the molecular mechanisms of presynaptic LTP that circumvents many of these limitations.

In this study, we have, for the first time, acutely reconstituted mfLTP in the mature brain of a mutant mouse that normally lacks this form of LTP. We used the RIM $1 \alpha^{-1-}$ genetic background in these studies because to date, the mechanism by which RIM $1 \alpha$ is required for mfLTP is unknown. RIM $1 \alpha$ interacts with many presynaptic proteins that each could potentially be involved in mediating presynaptic long-term plasticity. For example, the interaction with $\alpha$-liprin, a protein involved in active zone organization (Zhen and Jin, 1999), suggests that RIM1 $\alpha$ may play a role in synapse formation. Because acute expression of RIM $1 \alpha$ in the mature brain can restore mfLTP, our results suggest that a role for RIM $1 \alpha$ in synapse development is unlikely to underlie its requirement for mfLTP.

We also used this approach to test whether there was evidence to support the idea that S413 of RIM1 $\alpha$ serves as a phosphorylation-dependent switch required for the expression of presynaptic LTP. This idea gained support from a series of studies that acutely rescued LTP in cerebellar cultures prepared from embryonic RIM $1 \alpha^{-1-}$ mice (Lonart et al., 2003; Simsek-Duran et al., 2004). However, in contrast to this idea, both cerebellar parallel fiber and hippocampal mossy fiber LTP were intact in the genetic knockin mouse, which contained an S413A mutation in the RIM1 gene (Kaeser et al., 2008). Here, we show that two mutations interfering with the phosphorylation-dependent signaling of RIM1 $\alpha$ serine 413 (S413A and V415P) are both capable of restoring presynaptic LTP acutely using intact, postdevelopment brain circuitry. These findings are in agreement with the S413A knockin mouse study and bypass concerns about developmental compensation.

Several differences remain between the two acute genetic rescue approaches that might account for the divergent results. For example, plasticity mechanisms might be different between cerebellar granule cell-Purkinje cell synapses and hippocampal mossy fiber synapses; although in brain slice studies, parallel fiber and mossy fiber LTP appear to have shared mechanisms and the S413A knockin mutation left LTP intact at both of these sites (Nicoll and Schmitz, 2005; Kaeser et al., 2008). Alternatively, plasticity mechanisms might differ between neurons cultured from embryonic tissue and those from intact adult brain slices. Last, mechanisms responsible for the divergent results might engage in the $1 \mathrm{~d}$ window between the time of the cultured neuron observations (20-54 h) and our mfLTP recording period $(4-7 \mathrm{~d})$.

In summary, we show for the first time that mfLTP can be reconstituted de novo in the mature brain of mice normally lacking this form of plasticity. Our results demonstrate that the role of RIM $1 \alpha$ in mfLTP is not due to a requirement for RIM $1 \alpha$ during the major period of brain development. Using this acute rescue approach, we provide two lines of evidence that phosphorylation of RIM1 $\alpha$ S413 is not required for mfLTP, indicating that the mechanism for the requirement of PKA in presynaptic LTP is still unknown. Our approach provides a useful tool in the otherwise limited armamentarium to pursue this question as well as investigate more generally the mechanisms of presynaptic long-term plasticity. 


\section{References}

Betz A, Thakur P, Junge HJ, Ashery U, Rhee JS, Scheuss V, Rosenmund C, Rettig J, Brose N (2001) Functional interaction of the active zone proteins Munc13-1 and RIM1 in synaptic vesicle priming. Neuron 30:183-196.

Castillo PE, Janz R, Südhof TC, Tzounopoulos T, Malenka RC, Nicoll RA (1997) Rab3A is essential for mossy fibre long-term potentiation in the hippocampus. Nature 388:590-593.

Castillo PE, Schoch S, Schmitz F, Südhof TC, Malenka RC (2002) RIMlalpha is required for presynaptic long-term potentiation. Nature 415:327-330.

Chevaleyre V, Heifets BD, Kaeser PS, Südhof TC, Purpura DP, Castillo PE (2007) Endocannabinoid-mediated long-term plasticity requires cAMP/ PKA signaling and RIM1alpha. Neuron 54:801-812.

Coppola T, Magnin-Luthi S, Perret-Menoud V, Gattesco S, Schiavo G, Regazzi R (2001) Direct interaction of the Rab3 effector RIM with $\mathrm{Ca}^{2+}$ channels, SNAP-25, and synaptotagmin. J Biol Chem 276:32756-32762.

Dryga SA, Dryga OA, Schlesinger S (1997) Identification of mutations in a Sindbis virus variant able to establish persistent infection in BHK cells: the importance of a mutation in the nsP2 gene. Virology 228:74-83.

Dumas T, McLaughlin J, Ho D, Meier T, Sapolsky R (1999) Delivery of herpes simplex virus amplicon-based vectors to the dentate gyrus does not alter hippocampal synaptic transmission in vivo. Gene Ther 6:1679-1684.

Fourcaudot E, Gambino F, Humeau Y, Casassus G, Shaban H, Poulain B, Lüthi A (2008) cAMP/PKA signaling and RIM1alpha mediate presynaptic LTP in the lateral amygdala. Proc Natl Acad Sci USA 105: 15130-15135.

Fusi S, Drew PJ, Abbott LF (2005) Cascade models of synaptically stored memories. Neuron 45:599-611.

Gibson HE, Reim K, Brose N, Morton AJ, Jones S (2005) A similar impairment in CA3 mossy fibre LTP in the R6/2 mouse model of Huntington's disease and in the complexin II knockout mouse. Eur J Neurosci 22: 1701-1712.

Huang YY, Li XC, Kandel ER (1994) cAMP contributes to mossy fiber LTP by initiating both a covalently mediated early phase and macromolecular synthesis-dependent late phase. Cell 79:69-79.

Jeromin A, Yuan LL, Frick A, Pfaffinger P, Johnston D (2003) A modified Sindbis vector for prolonged gene expression in neurons. J Neurophysiol 90:2741-2745.

Kaeser PS, Kwon HB, Blundell J, Chevaleyre V, Morishita W, Malenka RC, Powell CM, Castillo PE, Südhof TC (2008) RIM1alpha phosphorylation at serine-413 by protein kinase $\mathrm{A}$ is not required for presynaptic longterm plasticity or learning. Proc Natl Acad Sci U S A 105:14680-14685.

Kandel ER (2001) The molecular biology of memory storage: a dialogue between genes and synapses. Science 294:1030-1038.

Kim J, Dittgen T, Nimmerjahn A, Waters J, Pawlak V, Helmchen F, Schlesinger S, Seeburg PH, Osten P (2004) Sindbis vector SINrep(nsP2S $\left.{ }^{726}\right)$ : a tool for rapid heterologous expression with attenuated cytotoxicity in neurons. J Neurosci Methods 133:81-90.

Kiyonaka S, Wakamori M, Miki T, Uriu Y, Nonaka M, Bito H, Beedle AM, Mori E, Hara Y, De Waard M, Kanagawa M, Itakura M, Takahashi M, Campbell KP, Mori Y (2007) RIM1 confers sustained activity and neurotransmitter vesicle anchoring to presynaptic $\mathrm{Ca}^{2+}$ channels. Nat Neurosci 10:691-701.

Lissin DV, Gomperts SN, Carroll RC, Christine CW, Kalman D, Kitamura M, Hardy S, Nicoll RA, Malenka RC, von Zastrow M (1998) Activity differentially regulates the surface expression of synaptic AMPA and NMDA glutamate receptors. Proc Natl Acad Sci U S A 95:7097-7102.

Lonart G, Schoch S, Kaeser PS, Larkin CJ, Südhof TC, Linden DJ (2003) Phosphorylation of RIMlalpha by PKA triggers presynaptic long-term potentiation at cerebellar parallel fiber synapses. Cell 115:49-60.

Marie H, Morishita W, Yu X, Calakos N, Malenka RC (2005) Generation of silent synapses by acute in vivo expression of CaMKIV and CREB. Neuron 45:741-752.

Nguyen PV, Woo NH (2003) Regulation of hippocampal synaptic plasticity by cyclic AMP-dependent protein kinases. Prog Neurobiol 71:401-437.

Nicoll RA, Schmitz D (2005) Synaptic plasticity at hippocampal mossy fibre synapses. Nat Rev Neurosci 6:863-876.

Ohtsuka T, Takao-Rikitsu E, Inoue E, Inoue M, Takeuchi M, Matsubara K, Deguchi-Tawarada M, Satoh K, Morimoto K, Nakanishi H, Takai Y (2002) Cast: a novel protein of the cytomatrix at the active zone of synapses that forms a ternary complex with RIM1 and munc13-1. J Cell Biol 158:577-590.

Pettit DL, Perlman S, Malinow R (1994) Potentiated transmission and prevention of further LTP by increased CaMKII activity in postsynaptic hippocampal slice neurons. Science 266:1881-1885.

Rhee JS, Betz A, Pyott S, Reim K, Varoqueaux F, Augustin I, Hesse D, Südhof TC, Takahashi M, Rosenmund C, Brose N (2002) Beta phorbol esterand diacylglycerol-induced augmentation of transmitter release is mediated by Munc13s and not by PKCs. Cell 108:121-133.

Schoch S, Castillo PE, Jo T, Mukherjee K, Geppert M, Wang Y, Schmitz F, Malenka RC, Südhof TC (2002) RIMlalpha forms a protein scaffold for regulating neurotransmitter release at the active zone. Nature 415:321-326.

Simsek-Duran F, Linden DJ, Lonart G (2004) Adapter protein 14-3-3 is required for a presynaptic form of LTP in the cerebellum. Nat Neurosci 7:1296-1298.

Sudhof TC (2004) The synaptic vesicle cycle. Annu Rev Neurosci 27: $509-547$.

Sun L, Bittner MA, Holz RW (2003) Rim, a component of the presynaptic active zone and modulator of exocytosis, binds 14-3-3 through its $\mathrm{N}$ terminus. J Biol Chem 278:38301-38309.

Takahashi T, Svoboda K, Malinow R (2003) Experience strengthening transmission by driving AMPA receptors into synapses. Science 299: 1585-1588.

Tzounopoulos T, Janz R, Südhof TC, Nicoll RA, Malenka RC (1998) A role for cAMP in long-term depression at hippocampal mossy fiber synapses. Neuron 21:837-845.

Villacres EC, Wong ST, Chavkin C, Storm DR (1998) Type I adenylyl cyclase mutant mice have impaired mossy fiber long-term potentiation. J Neurosci 18:3186-3194.

Wang X, Hu B, Zimmermann B, Kilimann MW (2001) Riml and rabphilin-3 bind Rab3-GTP by composite determinants partially related through N-terminal alpha-helix motifs. J Biol Chem 276:32480-32488.

Wang Y, Okamoto M, Schmitz F, Hofmann K, Südhof TC (1997) Rim is a putative Rab3 effector in regulating synaptic-vesicle fusion. Nature 388: 593-598.

Wang Y, Sugita S, Sudhof TC (2000) The RIM/NIM family of neuronal C2 domain proteins. Interactions with Rab3 and a new class of Src homology 3 domain proteins. J Biol Chem 275:20033-20044.

Wang Y, Liu X, Biederer T, Südhof TC (2002) A family of RIM-binding proteins regulated by alternative splicing: implications for the genesis of synaptic active zones. Proc Natl Acad Sci U S A 99:14464-14469.

Weisskopf MG, Nicoll RA (1995) Presynaptic changes during mossy fibre LTP revealed by NMDA receptor-mediated synaptic responses. Nature 376:256-259.

Weisskopf MG, Castillo PE, Zalutsky RA, Nicoll RA (1994) Mediation of hippocampal mossy fiber long-term potentiation by cyclic AMP. Science 265:1878-1882.

Wimmer VC, Nevian T, Kuner T (2004) Targeted in vivo expression of proteins in the calyx of Held. Pflugers Arch 449:319-333.

Young SM Jr, Neher E (2009) Synaptotagmin has an essential function in synaptic vesicle positioning for synchronous release in addition to its role as a calcium sensor. Neuron 63:482-496.

Zhen M, Jin Y (1999) The liprin protein SYD-2 regulates the differentiation of presynaptic termini in C. elegans. Nature 401:371-375. 